\title{
Primary health care in a changing world
}

This article considers the changing nature of primary health care in a changing international context. Four family physicians from four continents and all involved in the change process, reflect on the developments in primary health care as they perceive them. Jan De Maeseneer was involved in the incremental strengthening of primary health care in Belgium and has an international perspective as Chairman of the European Forum for Primary Care. Shabir Moosa is the acting chief specialist of District Health Services in Gauteng (South Africa) and coordinates a project on strengthening family medicine training in Africa. Yongyuth Pongsupap is the primary care component manager of Health Care Reform Project and expert in health policy at the National Health Security Office in Nonthaburi (Thailand). He has been working as a GP in a new established health centre since he was assigned as a pilot family doctor in 1991. Arthur Kaufman is involved in programmes for better access to health care for vulnerable groups and in primary care innovations in the state of $\mathrm{New}$ Mexico (US).

\section{CHALLENGES FOR PRIMARY HEALTH CARE IN A CHANGING WORLD}

Today, we face unprecedented demographic and epidemiologic transitions. The world population is aging rapidly. In $2005,19 \%$ of all deaths were among children and $53 \%$ were among people aged 60 years and older. By 2030 the respective proportions will have changed to $9 \%$ and $62 \% .^{1}$ Noncommunicable disease mortality will increase from $61 \%$ to $68 \%$ worldwide, and a similar trend will occur in Africa despite the HIV/AIDS pandemic and poor socioeconomic circumstances. As the population ages, the number of people with multimorbidity (two or more chronic conditions) will increase. ${ }^{2}$ There are wide differences in healthy life expectancy across the world: for Africa, healthy life expectancy is 40 years for males and 42 years for females, for Europe it is 62 and 68 years respectively. ${ }^{3}$ Encouragingly, the number of deaths from HIV/AIDS fell from 3.9 million in 2001 to 2.1 million in $2007 .{ }^{4}$ More worrying is the fact that indicators tell us that the Millennium Development Goals will not be met by 2015 . All regions are lagging on at least some of the goals with two regions off track on all the goals (South-Asia and sub-Saharan Africa). ${ }^{5}$

Scientific and technological innovations bring the prospect of new prevention and care possibilities. Greater understanding of the role that genes play in health and disease is likely to have an enormous influence on health care, especially in terms of diagnosis and prognosis. Information and communication technology creates opportunities for more thorough and consistent documentation of decisions at the point of care, better continuity of care, and more effective communication between organisations and sectors. Diagnostic innovations like CT and MRI scanning make invasive (and often painful) diagnostic tests obsolete and nearpatient testing creates timely and costeffective opportunities for the improvement of diagnostic accuracy. New drug treatments are emerging and may change the approach to diseases (replacing surgery with medical treatment: for example proton pump inhibitors). The development of evidence-based medicine, and the rapid growth of the knowledge base in many specialties, has provided important tools to make health care more consistent, effective, and cost-effective. But while these developments offer many opportunities for improving health outcomes, there are concerns about the extent to which the needs of developing countries are taken into account in the setting of research agendas, and to which all these developments are market-driven rather than needs-driven.

One of the most important cultural developments is that 'patients' are acting more and more as 'consumers'. ${ }^{6}$ This has consequences for the expectations and demands at the point of service delivery. Both in high and low income countries there is an increasing medicalisation of daily life (for example, through the creation of 'new diseases'). ' In terms of socioeconomic developments, the gap between rich and poor is widening, and there is a growing concentration of wealth (and consequent power over health policy decisions) at the top of the income distribution. We are living in a 'risk society' with ecological (food safety, climate change, water and air pollution), socioeconomic and individualisation risks. ${ }^{8}$ More and more people are living with a risk of poverty, certainly when they have 'unstable' jobs. In urban areas, up to half of the population live in one-person-'families', with insufficient social tissue to support them in case of disease.

Finally, an important challenge comes from globalisation and 'glocalisation'. Changes in economic policy have led to increasing participation of low- and middle-income countries in the global economy. However, when comparing the period of 1960-1980 with the rapidly globalising period of 1980-2000, growth in per capita GDP has slowed, and this has been accompanied by a slowing in progress in both health and educational outcomes. ${ }^{9}$ Ethnic conflict and war in many parts of the world have led to high levels of mobility and migration, which have greatly added to the general escalation of migration trends. There is also a growing urbanisation of the world's population. Today $50 \%$ of the world population live in cities, by 2030 the figure will be $70 \%$. This means that (primary) healthcare systems will be faced with new challenges as the global problems become apparent at a more concentrated, local level ('glocalisation'). Globalisation induces a change in health need (such as more complex diagnosis and intercultural communication problems). Moreover the globalised world needs 'preparedness' focusing on the prevention and/or the rapid 
and appropriate response to disease outbreaks and disasters (for example, pandemic influenza and bioterrorist activity).

\section{HOW DOES PRIMARY HEALTH CARE RESPOND TO THE CHALLENGES OF THE CHANGING WORLD?}

Twelve characteristics ${ }^{10}$ define primary health care: it is general in scope, accessible, integrated (including health promotion, disease prevention, cure and care, rehabilitation and palliation), continuous, dependent on teamwork, holistic, personal (focusing on the person rather than the disease), family and community oriented, coordinated, confidential (respecting the patient's privacy), and plays an advocacy role. ${ }^{11}$ The relevance of some of those principles is challenged by our changing world:

- a 'general' approach at a time when subspecialisation is booming;

- 'accessible' to different cultural and social groups at a time when cultural diversity is seen by some as a threat rather than as an opportunity;

- 'integrated' in a framework where there is increasing fragmentation with marketdriven 'for profit' stand-alone facilities;

- 'continuous' at a time when people are constantly on the move and 'care from the cradle to the grave' sounds very outdated;

- 'family orientated' at a time when the traditional family is no longer the prevailing living unit; and

- 'coordinated' at a time when quality of care for the patient with multimorbidity is often judged against guidelines created for the management of single diseases.

This study explores how, in different continents, primary healthcare stakeholders have responded to these challenges. In each example, we address relevance, equity (including accessibility), quality and cost-effectiveness.
In Thailand, in the 1990s, the government was convinced that change in the healthcare system was needed and primary health care was at the forefront of that change. The aims were threefold: to increase equity, improve quality and give a human dimension to health care (Appendix 1). Physicians moved outside the hospital setting and there was a shift from the 'specialist in the hospital' to the 'family practitioner in the community'. Capacity problems were addressed via an intensive training and support programme.

In South Africa, the political change at the end of apartheid placed equity on the health policy agenda (Appendix 2). Primary health care developed at the different levels. The government embraced primary health care in its health strategy and university and training institutions developed training programmes for family physicians, primary care nurses and midlevel care workers.

In the US, primary health care has traditionally been very weak. The poor outcomes of its technology-driven and market-orientated healthcare system, requested the adoption of the concept of the primary care 'medical home' system to coordinate care. ${ }^{12}$ This concept is applied differently in different states. For example, in New Mexico, it is an integral part of a strategy to address the challenges of cultural diversity and geographic and financial barriers to adequate health care. The University of New Mexico developed a web-based primary care referral programme intended to connect the uninsured to a 'medical home'. The 'Health Commons', a community-based care, attempts to address the social determinants of disease by creating a seamless system of social, behavioural and medical service for the indigenous, uninsured and undocumented (illegal) population, is a new concept that uses an intersectoral approach (Appendix 3).

In Belgium, which lacked a comprehensive structural framework for primary care (for example: no patient lists, no gatekeeping function, and a fee-forservice system with a focus on curative services), an incremental approach to strengthen primary care has been developed, focusing mainly on improving access and quality assurance. But implementation of this strategy has been difficult as the policy framework requires continuous compromise between insurance organisations and health professions. In parallel with the traditional fee-for-service system, innovative primary healthcare centres have been introduced, which work on a mixed capitation system (without financial disincentives), and which encourage an integrated approach with special attention for vulnerable groups. In order to address the causes of disease, the centres have developed a communityorientated primary care strategy, focusing on empowerment and social cohesion (Appendix 4).

\section{PRIMARY HEALTH CARE IN THE CHANGING WORLD: A SWOT ANALYSIS}

Although there are huge differences in the context in which primary health care has developed, the examples from four continents (Appendices 1-4) illustrate some common features of a primary healthcare based approach for the challenges of our changing world. For each system, it is important to monitor the impact on equity (access, reducing social inequalities in health), quality (both process and outcome) and morbidity and mortality. Looking at the examples, there is an interesting convergence: on the one hand countries with limited primary health care delivered mainly by nurses along with an overall healthcare system geared towards hospital care (for example, Thailand and South Africa) are increasingly recognising the value of a comprehensive, holistic primary healthcare team with a highly-trained clinician (the family physician). However, countries that traditionally offered strong personorientated office-based family physicians 
(Belgium, US) have discovered the need for a more interdisciplinary and community-orientated primary healthcare team, with greater involvement of the local population, and of the benefits of intersectoral action for health.

Primary health care has a lot of strengths especially as it practices a comprehensive patient-centred approach, and it has, at least in Western Europe, a strong historical development building on a variety of traditions. Since the 1990s it has developed a switch from 'experienced based medicine' toward 'evidence-based medicine', underpinning guidelines and protocols. A challenge is how to reconcile an evidence-based medicine approach with the important role traditional healers play in developing countries, where they are the first contact a person has with the healthcare system. Greater involvement of the patient (for example, through self-help groups), has become a cornerstone of the primary healthcare approach. An increasing community orientation and intersectoral action has contributed to closing the gap between primary health care and public health. ${ }^{13}$ This approach starts from information collected at the primary healthcare level, sometimes supplemented with surveys and focus groups. The information is then shared with the local community and a 'community diagnosis' is established. The local community participates in priority setting and developing an action plan. The results are monitored and may lead to changes in the local health policy. ${ }^{14}$ By doing so primary health care contributes to increased social cohesion and to people's empowerment. ${ }^{15}$

But there are also weaknesses: limited funding (leading to inadequate care with short consultations, under- and overservicing in relation to financial incentives) and limited capacity and capability of healthcare providers. There is a need for more emphasis on people-centred values, professionalism and humanism in a culture of care and communication. ${ }^{16}$ There are important gaps remaining between primary health care and public health; between health and welfare; between cure, care and promotion, and prevention. There are a variety of opportunities for primary health care nowadays: globalisation with increased possibility to network and exchange experiences is one of them. Moreover, the growing international political attention for the need of universal coverage in order to make health care accessible and the role primary health care can play in this is of utmost importance. The growing attention for (education in) interdisciplinary teamwork and task delegation, aiming at subsidiarity and patient management, creates possibilities for comprehensive chronic patient care. Experiments in different countries with intersectoral action for health, involving sectors such as urbanisation, economy, housing, and education at different levels of society creates a favourable environment for the development of strong primary health care.

However, important threats may challenge the future of primary health care: globalisation is both an opportunity and a threat (for example through the international brain drain). Solidarity and equity, underpinning the values of primary health care, are increasingly under pressure since 1989 , and certainly after the 9/11 events in 2001. Increasingly, all over the world market mechanisms are being introduced in primary health care. The challenges will be how these mechanisms may be able to contribute to the relevance, equity, quality and cost-effectiveness of the primary healthcare system and whether they will be a threat to a comprehensive and holistic approach. New initiatives such as 'walk-in clinics' although responding to the 'consumerism'-trend lead to fragmentation and are not cost-effective. Therefore, strengthening primary health care in Western countries is needed to rebuild a strong (national) health system, ${ }^{15}$ that resists 'the fragmentarisation of care caused by market competition through the restoration of personal continuity ... so that patients' life stories become central to information systems rather than disjointed episodes of repair'. ${ }^{17}$

In developing countries, there is an increasing tension between vertical disease-orientated programs (focusing on Aids, malaria, and tuberculosis) and the development of primary health care. In order to avoid 'internal brain drain' (from local primary care to vertical programs) investment of donors in strengthening primary health care is needed. ${ }^{18}$ World wide there is a continuous risk of underfunding primary health care both at the level of infrastructure and human resources.

\section{PRIMARY HEALTH CARE: NOW MORE THAN EVER}

Only a strong commitment of governments towards strengthening primary health care can achieve the objective of care that is relevant, equitable, high-quality, and costeffective. The World Health Report $2008^{19}$ may be a starting point for clear engagements to give a new impetus for primary health care in order to achieve the Millennium Development Goals. A worldwide global primary healthcare plan is needed, and the World Health Organization should set the agenda for this development, creating a specific primary healthcare department or unit that cuts across the vertical disease orientated programs in the organisation. There is a need for analysis of policy development and dissemination of best practices, using an open method of coordination. The Pan American Health Organization report 'Renewing primary health care in the Americas' has described how this could work for the Americas. ${ }^{20}$ An important effort is needed at the level of recruitment, education, and retention of primary healthcare workers: primary care nurses, family physicians, and mid-level care workers. Professional organisations (such as Wonca) and (networks of) universities and institutions for higher education (such as the Network Towards Unity for Health) should continue to demonstrate their 'social accountability' by training appropriate providers.

A clear research agenda has to be set at different levels: at the macro-level there is a need to understand better how sustainable primary healthcare-orientated health systems may be developed and how primary health care, through intersectoral action for health may contribute to address the social determinants of health. Research is needed to understand better how measures taken in different domains (finance, economy, and urbanisation) may affect health systems ('health system impact assessment'). At the meso-level, we need research about models that 
bridge the gap between primary health care and public health, that investigate how professionals, civil society organisations, and populations can interact to strengthen primary care, and what are the best ways of organising the 'microsystems' that deliver care (for which theories of complex adaptive systems may be helpful). ${ }^{21}$

At the micro-level a better understanding of how the concept of 'patient-orientation' can be put into practice in different cultures is needed alongside more insight concerning the experiences of patients in the healthcare system. A focus on evidence-based medicine and implementation of guidelines should complement, not replace 'contextual evidence'. ${ }^{22}$ Certainly for patients with multimorbidity, there is a need to deviate from the disease-orientated guidelines, integrating context as an important frame of reference.

Political will, sound research, committed providers and population-participation are needed to tackle the challenges of the changing world through comprehensive, accessible and quality primary health care.

We need it now more than ever.

\section{Jan De Maeseneer, Shabir Moosa, Yongyuth Pongsupap and Arthur Kaufman}

\section{Competing interests}

The authors have stated that there are none.

\section{REFERENCES}

1. Social and Cultural Planning Office. Social and cultural report 2000. The Hague: Social and Cultural Planning Office, 2000

2. Van den Akker M, Buntinx F, Metsemakers JF, et al. Multimorbidity in general practice: prevalence, incidence and determinants of co-occurring chronic and recurrent diseases. J Clin Epidemiol 1998; 51(5): 367-375.

3. World Health Organization. World Health Statistics 2006. Geneva: WHO, 2006

4. United Nations. Declaration of Commitment on HIV/Aids and political declaration on HIV/Aids: midway to the Millennium Development Goals. New York, NY: United Nations, General Assembly, 2008.

5. The International Bank for Reconstruction and Development/The World Bank. Global Monitoring report 2006: Millennium Development Goals: strengthening mutual accountability, aid trade and governance. Washington, DC: IBRD, 2006.

6. Greenhalgh T, Wessely S. 'Health for me': a sociocultural analysis of healthism in the middle classes. Br Med Bull 2004; 69:197-213.

7. Moynihan R. The making of a disease: female sexual dysfunction. BMJ 2003; 326: 45-47.

8. Beck U. Risk society: towards a new modernity.
London, Sage Publications, 1992.

9. Weisbrot M, Baker D, Kraev E, Chen J. The scorecard on globalization 1980-2000: its consequences for economic and social Well-being. In: Navarro V, Muntaner C. Political and economic determinants of population health and well-being: controversies on developments. New York, NY: Baywood Publishing Company, 2004: 91-114.

10. Starfield B. Primary care: balancing health needs, services and technology. New York, NY: Oxford University Press, 1998

11. Wonca Europe. The European definition of general practice/family medicine. London: Wonca Europe, 2002. http://www.globalfamilydoctor.com/ publications/Euro_def.pdf (accessed 1 Oct 2008)

12. Swieskowski, D. Mercy clinics: the medical home. Redesigning primary care delivery systems for patient centredness. Group Practice Journal 2008; 57(4): 13-17.

13. Van Weel C, De Maeseneer J, Roberts R. Integration of personal and community health care. Lancet 2008 372: 871-872.

14. Rhyne R, Bogue R, Kukulka G, Fulmer H. Community-oriented primary care: health care for the 21st century. Washington, DC: American Association for Public Health, 1998.

15. De Maeseneer J, Willems S, De Sutter A, et al. Primary health care as a strategy for achieving equitable care: a literature review commissioned by the Health Systems Network. http://www.who.int/ social_determinants/resources/csdh_media/primary_ health_care_2007_en.pdf (accessed 1 Oct 2008).

16. Omi S. People-centred health care: a policy framework. Geneva: WHO (Regional Committee for the Western Pacific), 2007.

17. Hart JT. Worlds of difference. Lancet 2008; 371: 1883-1885.

18. De Maeseneer J, van Weel C, Egilman D, et al. Funding for primary health care in developing countries: Money from disease specific projects could be used to strengthen primary care. $B M J 2008$; 336: 518-519.

19. World Health Organization. The world health report. Geneva: WHO, 2008. http://www.who.int/whr/en/ (accessed 13 Oct 2008).

20. Pan American Health Organization. Renewing primary health care in the Americas: a position paper of the Pan American Health Organization/World Health Organization. Washington DC; PAHO, 2007.

21. Anderson A, McDaniel RR Jr. Managing health care organisations: where professionalism meets complexity science. Health Care Manage Rev 2000; 25(1): 83-92.

22. De Maeseneer J, van Driel ML, Green LA, van Weel C. The need for research in primary care. Lancet 2003; 362: 1314-1319.

DOI: 10.3399/bjgp08X342697

\section{WHY PALLIATIVE CARE?}

'It's a fascinating line of work - in a truly humanistic way, you really feel you do achieve something. And every person with a life-threatening illness presents a new challenge. I end up by seeing the more difficult ones, the ones with complex pain. Lots of psychological angst that manifests itself in physical symptoms. I see people who are getting buckets of drugs and nothing works - and you know and they know the drugs are not the issue. There's nothing more satisfying than working someone around, whose pain ends up being well controlled on a minimal amount of drugs, because you've dealt with the underlying psychological and existential issues. In fact, it's addictive doing this work.

Actually knowing when someone is dying is the hardest thing, recognising that there's nothing more you're going to do to change the course of events. That's the biggest barrier - and that's what I do day after day, helping nurses to come to the realisation that 'hey, guys, we've done all we can for this patient now - there isn't anything more and the kindest thing is to back off.' Some families can be very pushy about wanting to maintain treatment that's futile, so it's being able to recognise when it is - and convey that to families and patients. You have to be very clear in your own mind that this is where you're at - and that's hard.'

\section{Ann Richardson}

From Life in a Hospice: reflections on caring for the dying by Ann Richardson. Published by Radcliffe Publishing at £19.95. (ISBN 9781846192432).

Highly Commended in the Medicine section of the 2008 BMA Book Awards.

DOI: 10.3399/bjgp08X342705 
Appendix 1. Thailand.

In Thailand, until the 1990s, primary health care consisted of health centres that started out as 'antennas of hospitals.' The focus of the care was on technical adequacy and clinical decisions, not on patient centeredness and quality of human relations. Family medicine appeared as a new specialty in Thailand in 1998. The first health centre to feature the family practice model was established in 1991. It was intended as a step towards changing the healthcare system. ${ }^{1}$ Today, family medicine, embedded in primary health care, belongs to the Thai health vocabulary and committed family practices give substance to the concept and function as demonstration and training centres. Health policy explicitly links universal coverage, first-line health service strengthening and family medicine development. Family medicine has seen an academic breakthrough and is now recognised as a speciality in its own right. The Ministry of Public Health views family practice as having the potential to transform healthcare delivery in Thailand in order to bring a new style of relating to patients along with a renewed understanding of the process of health and illness, and a new emphasis on illness prevention and coordination of care. They hope family practice will lead to improved access to care, increased emphasis on prevention at the community level and reduce the cost of care.

In contrast to the Western model of family practice (which remains largely focused on point-of-contact care) in most areas of Thailand, health needs and limited resources amplify the importance of action at the community level. Physicians must be able to move outside the hospital setting, conceptually and literally, in order to have an impact on the health problems of the communities they serve. ${ }^{2}$

Due to the increased focus on family medicine development under the new Thai Universal Coverage policy, primary care units were strengthened, shifting the centre from specialist-in-hospital to family practitioner-in-community. The emphasis on primary care in the Universal Coverage scheme represents a bold departure from the traditional, hospital-dominated Thai healthcare system. Initial problems with this new scheme included a shortage of doctors to staff primary care units, necessitating the use of hospital doctors who rotated out to the clinics. The doctors were too few in number and they lacked both the skills and orientation towards the integration of prevention and health promotion. Nurses and health workers serve as the backbone of service delivery at primary care level. Up until now high level policy makers have not been prepared to put in place the staff management mechanisms needed to support such redeployment, ${ }^{3}$ and institutional capacity for this change is not currently adequate. Moreover, stewardship and regulatory functions are still weak without clear definitions of the benefits package for primary care, its goals and operational targets, how to monitor indicators, and what rewards and sanctions there will be if quality is not maintained. These unfinished agenda items need very careful monitoring and evaluation for further improvement of the overall system to promote family practice until it becomes the standard of service of the Thai healthcare system.

\section{REFERENCES}

1. Pongsupap Y. Introducing a human dimension to Thai health care: the case for family practice [PhD thesis]. Brussels: VUBPRESS, 2007.

2. Williams RL, Henley E, Prueksaritanond S, Aramrattana A. Family practice in Thailand: will it work? J Am Board Fam Pract 2002; 15(1): 73-76.

3. Towse A, Mills A, Tangcharoensathien V. Learning form Thailand's health reforms. BMJ 2004; 328(7431): 103-105.

DOI: 10.3399/bjgp08X342697

\section{Appendix 2. South Africa.}

Primary health care originated in South Africa in the 1930s with the development of community-orientated primary health care albeit later smothered under apartheid. ${ }^{1}$ Family medicine has since been limited to private practice. The NHS since the 1990s is struggling to transform apartheid hospital-centric care towards primary health care. Previously, this was mainly organised to nurse-based clinics (with doctor visits) in the framework of the health districts. There is a strong community and programmatic orientation in the District Health Services however this is increasingly limited by few doctors visiting clinics, patient complaints about the clinical quality, verticalisation of disease-orientated programmes and with patients bypassing clinics to get to doctor-based hospitals.

Family medicine, now formally a specialist discipline since 2007 and progressively embracing the challenges of a new South Africa, is in a growing partnership between universities and provincial Departments of Health since the 2000s. Family physicians are based across district hospitals, community health centres, clinics and communities in order to improve quality of clinical care in an integrated model of care. Family physicians offer nurses clinical supervision, referral support and links to district hospitals. District Health Services and family medicine principles are growing in alignment. However, family physicians are also grappling with role definitions and clinical teamwork. Appropriately trained family nurse practitioners are producing access, higher quality health care and outcomes but there are cautions regarding the equivalence of care and productivity savings versus salary differentials. ${ }^{2,3}$ The clinical associate (mid-level worker) is also a part of this mix in the light of doctor shortages and is being supported by family physicians in South Africa as procedural assistant in district hospitals. ${ }^{4}$ The private health sector (consuming more than $60 \%$ of health-expenditures and serving less than $10 \%$ of the population mostly with specialist hospital care) is embracing primary health care to manage costs but has still to awaken to the renewed role of family physicians - the ability to balance costs, quality and access to health care with clinical teamwork. ${ }^{5}$

\section{REFERENCES}

1. Moosa SAH. Community-Oriented Primary Care (COPC) in district health services of Gauteng, South Africa. South African Family Practice 2006; 48(4): 6-11.

2. Horrocks S. Systematic review of whether nurse practitioners working in primary care can provide equivalent care to doctors. BMJ 2002; 324: $819-823$.

3. Mash R, Downing R, Moosa S, De Maeseneer J. Exploring the key principles of family medicine in sub-Saharan Africa: international Delphi consensus process. South African Family Practice 2008; 50(3): 60-65.

4. Hugo J. Mid-level health workers in South Africa: not an easy option. The South African Health Review. Durban: Health Systems Trust, 2005; Chapter 11: 149-158.

5. Lewis D. Case: In the large merger between Medicross Healthcare Group (Pty)Ltd and Prime Cure Holdings (Pty) Ltd. Competition Tribunal, Republic of South Africa, 2005. http://www.saflii.org/za/cases/ZACT/2005/66.pdf (accessed 2 Oct 2008). 


\section{Appendix 3. The US.}

The US is grappling with the most expensive system of health care in the world. Consuming $16 \%$ of the gross domestic product, it performs poorly compared to other industrialised countries. The US has no universal system of health care, no guaranteed access to basic services, and 47 million of its people have no health insurance. Policies established long ago favour overuse of expensive technologies in the face of underfunding of prevention and primary care. High levels of debt upon graduation and high income disparities between procedural specialties and primary care (being almost $4: 1$ ) tend to attract medical graduates to the more lucrative subspecialties. Whereas the primary care physician workforce comprises about $40-50 \%$ of all doctors in Canada and the UK, it is at about $25 \%$ and falling in the US. With a dearth of primary care doctors, there is a growing use of expensive emergency rooms for primary care needs.

New Mexico represents the extreme of healthcare challenges in the US. It is a large, but sparsely populated, poor, rural south-western state in which the majority of the population is ethnic minority (42\% Hispanic, $10 \%$ Native American and $2 \%$ African American), with linguistic, geographic and financial barriers to adequate healthcare. A substantial proportion of the population are illegal immigrants from Mexico and Latin America. While they form a vital part of the rural and urban economy, they are often ineligible for publicly funded health services so their use of primary and preventive services is very low. These special challenges have stimulated important innovations in primary care.

To connect the uninsured to a medical home, the University of New Mexico developed a web-based primary care referral program, called 'Primary Care Dispatch." It allows clerks discharging patients from the emergency room or hospital to assign them to a primary care medical home in their neighbourhood or community. This innovation has led to a $31 \%$ reduction in subsequent use of the emergency room by these patients.

The underlying social causes of ill health-such as poverty, racism, high income disparities and high dropout rates from school, are not addressed in the current healthcare system. However, they should be a central concern of primary care providers, as they are on the frontlines in terms of the impact on health in the community. Thus, the 'Health Commons' was created in New Mexico. ${ }^{2}$ It is a new concept in community-based care which attempts to address the social determinants of disease by creating a seamless system of social, behavioural and medical services for the indigenous, uninsured and undocumented (illegal) populations built around a primary care home. Community health priorities drive the clinic agenda and the community and clinic are linked by community health workers. Economic and community development are a feature of some of the sites, and employment and housing services and legal assistance are a component of others. Five Commons sites have been introduced so far, and more are planned.

\section{REFERENCES}

1. Murnik M, Randal F, Guevara M, et al. Web-based primary care referral program associated with reduced emergency department utilization. Fam Med 2006, 38(3):185-189.

2. Kaufman A, Derksen D, Alfero C, et al. The health commons and care of New Mexico's uninsured. Ann Fam Med 2006; 4(Suppl 1): S22-S27.

DOI: 10.3399/bjgp08X342697

\section{Appendix 4. Belgium.}

In Belgium, the last 30 years have seen a very laborious development of primary health care; the hospital-centric systems with direct access to any provider or facility for the patient, operating in a fee-for-service system with a $30 \%$ cost-share by the patient, has not been a favourable environment for the development of primary health care. This system has been maintained through continuous negotiations where insurers and professional organisations compromise over the development of the fee-for-service system. In Belgium, initiatives by motivated health professionals and by civil society begun the development of interdisciplinary 'community health centres', with a focus on equity and community participation. The health centres negotiated the creation of a capitation system, without financial disincentive, for registered patients. This optimised access to care, especially for the socially vulnerable groups. With an increasing attention to equity in health care, mechanisms were established by the government to enhance insurance (with almost $100 \%$ coverage) and to stimulate access and quality. Accessible care was developed for 'illegal people', offering them access for 'urgent medical care'. But in practice, this concept was interpreted as 'all the care needed'. Apart from personal care, orientated towards individuals and groups, community-orientated primary care actions were developed. Examples are: actions to address the poor physical health of youth through the creations of playgrounds and organisation of activities and actions to improve access to dental care. ${ }^{1}$ Currently the focus is on strengthening home care, development of disease management and implementation of guidelines with a focus on quality improvement. A fundamental bottleneck is the distribution of the political decisions over different levels: the federal government is responsible for the payment-mechanisms of healthcare providers and hospitals, whereas the regional government holds responsibility for prevention, organisation of home care and nursing homes and ambulatory mental health care. The same institution may be dependent on different authorities which hinders the development of a comprehensive care model. A global health plan, defining the objectives and targets for the future is missing.

\section{REFERENCE}

1. Art B, De Roo L, De Maeseneer J. Towards unity for health utilising community-oriented primary care in education and practice. Education for Health 2007; 20(2): 74. 